\title{
Temperature dependent flow softening of titanium alloy Ti6Al4V: An investigation using finite element simulation of machining
}

\author{
Yiğit Karpat* \\ Bilkent University, Department of Industrial Engineering, Ankara 06800, Turkey
}

\section{A R T I C L E I N F O}

\section{Article history:}

Received 23 April 2010

Received in revised form 2 December 2010

Accepted 7 December 2010

Available online 14 December 2010

\section{Keywords:}

Machining

Titanium alloys

Finite element modeling

Flow softening

\begin{abstract}
A B S T R A C T
Titanium alloy Ti6Al4V is the most commonly used titanium alloy in the aerospace and medical device industries due to its superior properties. There has been a considerable amount of research to better understand the serrated chip formation mechanism of titanium alloy Ti6Al4V by using finite element simulation of machining. An accurate representation of the behavior of the material is important in order to obtain reliable results from the finite element simulation. Flow softening behavior has been integrated into the material constitutive models to simulate adiabatic shear bands and serrated chips. Flow softening is usually related to the dynamic recrystallization phenomenon which initiates after a critical temperature. The aim of this study is to investigate the influence of various flow softening conditions on the finite element simulation outputs for machining titanium alloy Ti6Al4V. For this purpose, a new flow softening expression, which allows defining temperature-dependent flow softening behavior, is proposed and integrated into the material constitutive model. The influence of flow softening below the critical temperature, as adopted in recent studies, is also investigated. Various temperature-dependent flow softening scenarios are tested using finite element simulations, and the results are compared with experimental data from the literature. The results showed that the flow softening initiating around $350-500^{\circ} \mathrm{C}$ combined with appropriate softening parameters yields simulation outputs that agree well with the experimental measurements.
\end{abstract}

(c) 2010 Elsevier B.V. All rights reserved.

\section{Introduction}

An important goal in machining research is to eliminate expensive and time-consuming experimental modeling approaches in favor of physics-based machining models that are capable of producing realistic results at practical cutting conditions. One approach towards this goal is to develop finite element based machining models that rely on material constitutive models. Recently, Childs (2009) has shown that finite element models are capable of producing realistic results if the material behavior at high strains and strain rates is defined properly. It is not easy to replicate the deformation conditions typical in machining by using material testing procedures such as split bar Hopkinson tests. The behavior of the materials at high strains and strain rates is usually extrapolated based on these measurements, which may not yield reliable results when employed in finite element simulations of machining. Titanium alloy, which exhibits a different behavior at high strains and strain rates, is the subject of this study.

Titanium alloy Ti6Al4V has received particular consideration since it is a popular material in the aerospace and medical device

\footnotetext{
* Tel.: +9031229022 63; fax: +903122664054.

E-mail address: ykarpat@bilkent.edu.tr
}

industries. Moreover, it produces serrated chips under practical machining conditions, which makes it remarkable in terms of metal cutting research. Considering that the interaction between the cutting tool flank face and the workpiece affects the chatter stability of the process when machining materials such as titanium alloys at low cutting speeds, it becomes important to develop machining models that consider the physics of the process and allow detailed analysis of the machining process (Altintas et al., 2008). Finite element simulation is an indispensable tool because it not only enables simulating serrated chip formation, but it also allows inclusion of the cutting tool edge geometry in the analysis in order to predict process outputs.

In finite element models, serrated chips can be simulated by artificially modifying the material flow stress behavior at higher strains (at the level of strains common in machining, but those cannot be easily attained by standard material testing devices) and/or by integrating a damage criterion. The focus of this study is on investigating the influence of modified flow stress behavior at high strains through a parametric study.

Shivpuri et al. (2001) artificially modified the flow stress behavior as a function of temperature and simulated serrated chip formation. They suggested that microstructure transformation is responsible for flow softening at high strains. An identical approach was also used by Bäker et al. (2002), but neither of these stud- 


\begin{tabular}{ll} 
Nomenclature \\
$\alpha_{T}$ & thermal expansion \\
$\varepsilon$ & strain \\
$\dot{\varepsilon}$ & strain rate \\
$\dot{\varepsilon}_{0}$ & reference strain rate \\
$\lambda$ & thermal conductivity \\
$\mu$ & coefficient of friction \\
$\sigma$ & flow stress \\
$\sigma_{\mathrm{S}}$ & steady state flow stress \\
$A$ & Johnson-Cook material model coefficient \\
$B$ & Johnson-Cook material model coefficient \\
$C$ & Johnson-Cook material model coefficient \\
$D$ & Johnson-Cook material model coefficient \\
$n$ & Johnson-Cook material model coefficient (strain \\
& hardening index) \\
$m$ & Johnson-Cook material model coefficient (strain \\
& rate sensitivity) \\
$a$ & proposed material model coefficient \\
$b$ & proposed material model coefficient \\
$c$ & proposed material model coefficient \\
$d$ & proposed material model coefficient \\
$e$ & proposed material model coefficient \\
$l$ & proposed material model coefficient \\
$p$ & proposed material model coefficient \\
$q$ & proposed material model coefficient \\
$n^{*}$ & proposed material model coefficient (strain harden- \\
& ing index) \\
$k$ & softening function parameter \\
$r$ & softening function parameter \\
$F_{C}$ & width of cut \\
$F_{t}$ & cutting force \\
$E_{\mathrm{Y}}$ & thrust force \\
$c_{p}$ & Young's modulus \\
$T_{r}$ & heat capacity \\
& moom temperature \\
\hline & softening function parameter
\end{tabular}

ies proposed a mathematical model for flow softening. Rhim and Oh (2006) integrated the effect of flow softening due to dynamic recrystallization initiating after a critical strain value at temperatures higher than half of the melting temperature in the material model. They also included a damage model to increase the degree of serration. Calamaz et al. (2008) summarized various possible mechanisms that would lead to flow softening, such as the platelet kinking suggested by Miller et al. (1999). They also proposed a softening function integrated to the Johnson and Cook (1983) material model. The proposed material model assumes that flow softening exists at all temperature levels. They were able to simulate serrated chips that resembled experimental chips. On the other hand, thrust force predictions were lower than experimental cutting force data (during this paper's review process a further publication has appeared relating to those issues (Calamaz et al., 2010)). Wang et al. (2010) used the flow softening model proposed by Calamaz et al. (2008) for the micro cutting of copper based alloy. They emphasized the effect of elastic strains on the formation of serrated chips. They showed that shear band formation initiates from the outer surface of the chip and grows towards the cutting tool edge.

The serrated chip formation is closely related to the material properties of Ti6Al4V, including its low thermal conductivity, strain hardening and thermal softening behavior. According to Komanduri and Turkovich (1981), the serrated chip formation process starts by upsetting the material in front of the tool. When critical shear strain is attained at a certain temperature, thermoplastic instability occurs, and as a result the serrated chip forms and shear bands are observed. Studies on thermoplastic instability relate the formation and propagation of adiabatic shear bands to the dynamic recrystallization (DRX) phenomenon without ruling out the crack initiation. DRX is defined as the process of microstructure reformation and evolution resulting in newly crystallized small grains with very low dislocation density. Critical strain, strain rate and temperature are required for DRX to occur. A detailed literature review on thermoplastic instability can be found in Xu et al. (2008), in which some principal findings on adiabatic shear localization are summarized as: "(a) there is a strain-rate dependent critical strain for the development of shear bands; (b) grain refinement and amorphization occur in shear bands; (c) loss of stress-carrying capability is more closely associated with microdefects rather than with localization of strain; and (d) band development and band structures are material dependent" (Xu et al., 2008). Recently, Rittel et al. (2008) have presented evidence that DRX triggers adiabatic shear failure by observing dynamically recrystallized nanograins in titanium alloy Ti6Al4V subjected to impact loading only half of its failure strain. Medyanik et al. (2007) studied the interaction between strain rate and temperature for AISI 4340 steel and showed that the critical temperature for DRX to occur decreases with increasing strain rate but reaches a steady state at a limiting value. Liao and Duffy (1998) measured the temperatures in the adiabatic band region to be around $440-550^{\circ} \mathrm{C}$ for the Ti6Al4V. In general, recrystallization process in metals occurs about $0.4-0.5$ of the melting temperature of the material which is $499-589^{\circ} \mathrm{C}$ for Ti6Al4V alloy (melting temperature is $1922 \mathrm{~K}$ ) (Liao and Duffy, 1998). This temperature increase is sufficient to produce newly recrystallized grains in the shear bands. However, according to the findings of Medyanik et al. (2007), it may be possible that the critical temperature initiating DRX during machining can be even lower than $0.4-0.5$ of melting temperature since it is closely related to the strain rate.

Another flow softening mechanism observed in titanium alloys at high temperatures is globularization, which is governed by the alpha to beta transformation and sliding of grain boundaries (Song et al., 2009). The experiments conducted by Song et al. (2009) reveal the initiation of globularization between strain levels of 0.42-0.65 around $920-980^{\circ} \mathrm{C}$ under strain rate range of $0.01-101 / \mathrm{s}$. Song et al. (2009) identify the differences between dynamic recrystallization and globularization, stating that for the former, the critical strain is lower and mainly dependent on temperature and strain rate, whereas the latter is not very sensitive to deformation temperature and strain rate since it is controlled by dislocation glide.

The propagation of adiabatic shear bands has also been considered as a major ductile failure mechanism, one which results in material separation along the shear band associated with the void formation due to thermal softening and local melting of secondary phases (Giovanola, 1988).

The aim of this study is to investigate flow softening behavior especially, around and below critical DRX temperatures. For this purpose, a new softening function which allows introducing different material behavior at various temperature levels is proposed. Different softening scenarios are considered, and results of the finite element simulations are validated and tested under different machining conditions on two different experimental datasets from the literature.

\section{Material constitutive model}

In the literature, many material models have been proposed to define the relationship between strain, strain rate, and temperature. Johnson and Cook (1983) material model is the most popular 
Table 1

List of Johnson-Cook material model parameters reported for Ti6Al4V.

\begin{tabular}{|c|c|c|c|c|c|}
\hline$A(\mathrm{MPa})$ & $B(\mathrm{MPa})$ & $n$ & $C$ & $m$ & Ref. \\
\hline 782.7 & 498.4 & 0.28 & 0.028 & 1 & Umbrello (2008) \\
\hline 724 & 683.1 & 0.47 & 0.035 & 1 & Lee and Lin (1998) \\
\hline 968 & 380 & 0.421 & 0.0197 & 0.577 & $\mathrm{Li}$ and $\mathrm{He}(2006)$ \\
\hline 859 & 640 & 0.22 & 0.000022 & 1.1 & Ozel and Zeren (2004) \\
\hline 862 & 331 & 0.34 & 0.012 & 0.8 & Meyer and Kleponis (2001) \\
\hline 1098 & 1092 & 0.93 & 0.014 & 1.1 & Chen et al. (2004) \\
\hline 997.9 & 653.1 & 0.45 & 0.0198 & 0.7 & Seo et al. (2005) \\
\hline
\end{tabular}

one due to its simple form (Eq. (1)). It relates strain, strain rate and temperature to flow stress in a multiplicative form through the parameters $A, B, n, C$ and $m$. Some Johnson-Cook material model parameters calculated for Ti6Al4V titanium alloy are listed in Table 1. Even though some parameter sets are based on the same split Hopkinson bar test data, the calculated material model parameters are spread over a wide range of values due to possible differences in microstructures and/or the mathematical techniques used in calculating Johnson-Cook parameters. Hence, when used in finite element simulations, different simulation outputs are obtained for different material model parameters. Unfortunately, no microstructure information is available for the titanium alloy used in the study of Lee and Lin (1998) except that the material was received as annealed.

$\sigma=\left(A+B \varepsilon^{n}\right)\left(1+C \ln \left(\frac{\dot{\varepsilon}}{\dot{\varepsilon}_{0}}\right)\right)\left(1-T^{* m}\right)$

$T^{*}=\frac{T-T_{r}}{T_{m}-T_{r}}$

Anurag and Guo (2007) proposed a material model based on the microstructural properties of the titanium alloy Ti6Al4V as shown in Eq. (2). The advantage of using this material model is that it offers a methodology of calculating material model parameters. They obtained the relationship between strain and flow stress by considering the dynamic strain aging phenomenon where the flow stress becomes insensitive to strain at a certain temperature. Then a temperature function was added to include the influence of temperature on the flow stress.

$\sigma(\varepsilon, T)=f(T)\left(A \varepsilon^{n}\right)$

Karpat (2009) modified this model by recalculating the parameters based on the data of Lee and Lin (1998) and by adding the relationship between the strain and the strain rate through a $\tan h$ function as shown in Eq. (3). The coefficients of the material model are given in Table 2, which are calculated through an optimization algorithm.

$\sigma(\varepsilon, \dot{\varepsilon}, T)=\left(a \varepsilon^{n^{*}}+b\right)\left(c T^{* 2}+d T^{*}+e\right) h(\varepsilon, \dot{\varepsilon})$

$h(\varepsilon, \dot{\varepsilon})=\left(1-\left[1-\left(\frac{\ln \left(\dot{\varepsilon}_{0}\right)}{\ln (\dot{\varepsilon})}\right)^{q}\right]\left[\frac{1}{l * \tan h(\varepsilon+p)}\right]\right)$

$T^{*}=\frac{T}{T_{r}}$

The material model outputs at different temperature levels are given in Fig. 1(a); they are compared to split Hopkinson bar test results at various strain rates in Fig. 1(b), and also with

Table 2

The coefficients of the material model (Eq. (3)).

\begin{tabular}{lllll}
\hline$a(\mathrm{MPa})$ & $n^{*}$ & $b(\mathrm{MPa})$ & $c$ & $d$ \\
\hline 590 & 0.27 & 740 & $7.1903 \mathrm{e}-5$ & -0.0209 \\
$q$ & $l$ & $p$ & $\dot{\varepsilon}_{0}(1 / \mathrm{s})$ & $e$ \\
\hline 0.035 & 1.1 & 0.08 & 800 & 1.6356 \\
\hline
\end{tabular}

Johnson-Cook material model parameters reported by Lee and Lin (1998) in Fig. 1(c). It can be seen that the proposed material model can successfully represent flow stress behavior at low strains.

An appropriate modification must be included in the material model (Eq. (3)) to consider flow softening, which initiates after a critical strain and temperature. In order to be able to facilitate soft-
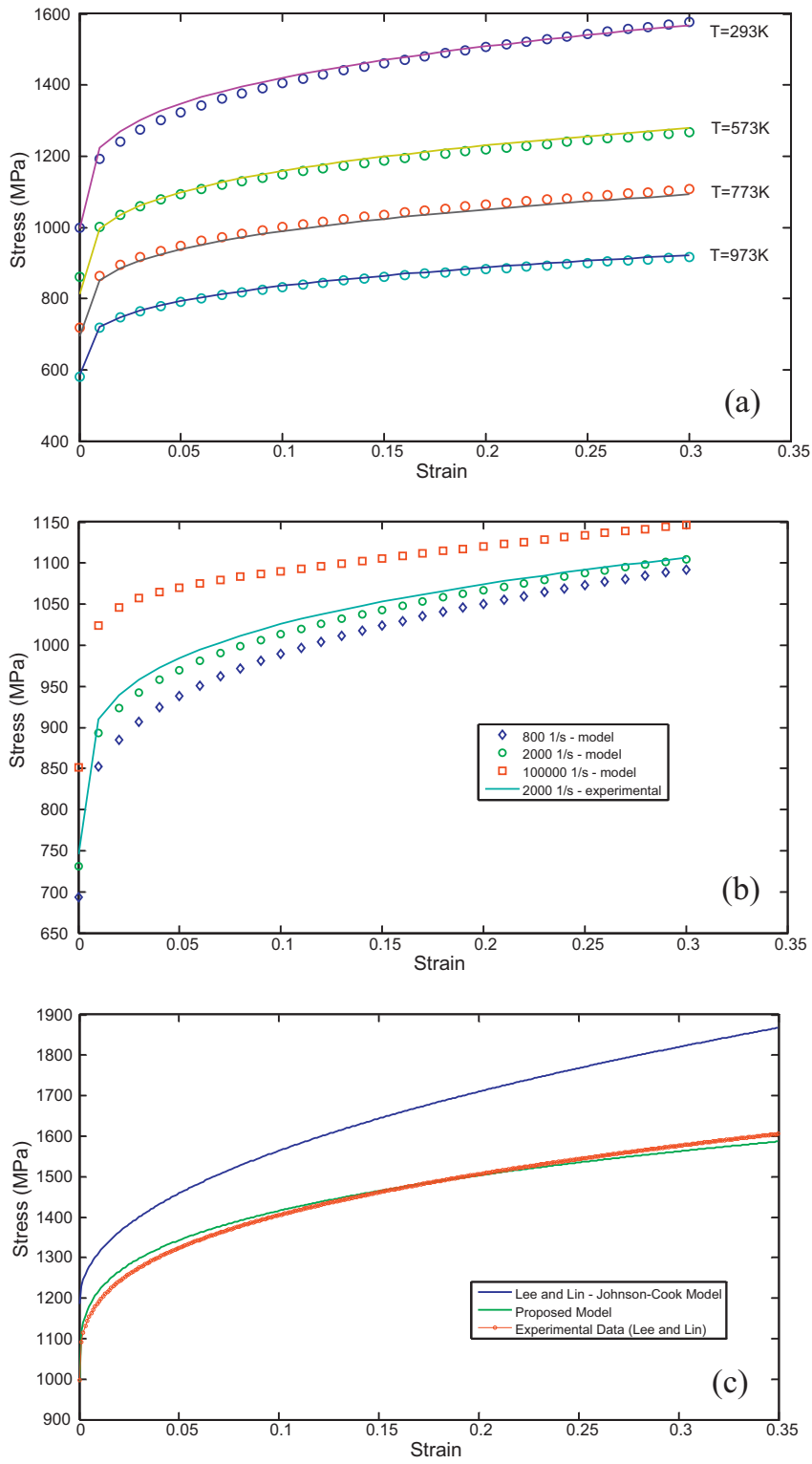

Fig. 1. The flow stress curves based on data of Lee and Lin (1998); (a) at various temperatures for the strain rate of $20001 / \mathrm{s}$, (b) at various strain rates for temperature $300^{\circ} \mathrm{C}$ and (c) comparison of flow stress curves obtained through Johnson-Cook material model parameters calculated by Lee and Lin (1998) and the proposed model (at $20^{\circ} \mathrm{C}$ and $8001 / \mathrm{s}$ ). 


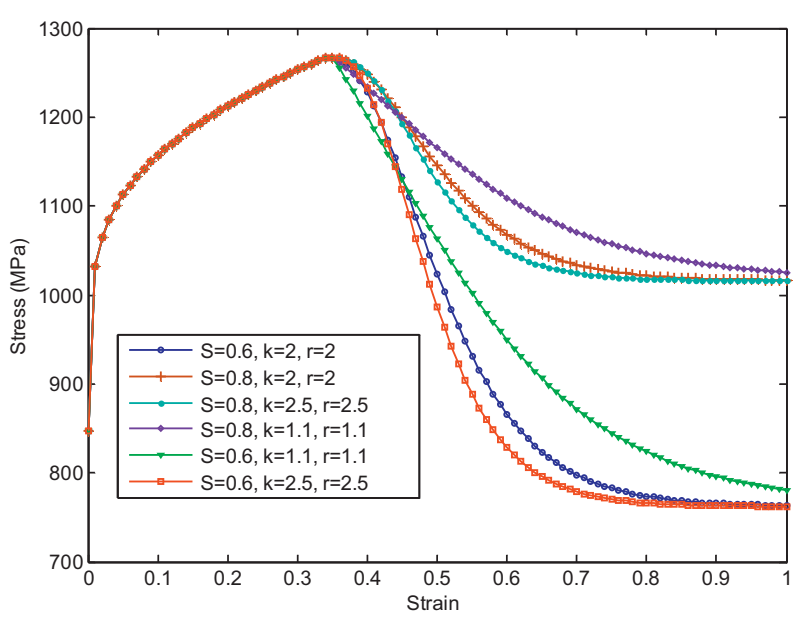

Fig. 2. Controlling the material behavior at high strains through the parameters $S$, $k$, and $r\left(\varepsilon_{\mathrm{cr}}=0.35,300^{\circ} \mathrm{C}, 20001 / \mathrm{s}\right)$.

ening at any strain and to have flexibility on the softening rate, a function is proposed. The proposed function has three parameters as $S, k$, and $r$ which control the softening behavior occurring after a critical strain value $\left(\varepsilon_{\mathrm{cr}}\right)$ as shown in Eqs. (4)-(6). The influence of these parameters on the flow stress curve is shown in Fig. 2 . It can be seen that $S$ value defines the steady state value of flow stress after softening. The parameters $k$ and $\mathrm{r}$ denote the transition between strain hardening and steady state flow stress behavior. This formulation allows flexibility in terms of modeling various flow softening scenarios and it is similar to the flow softening function proposed by Rhim and Oh (2006), but it has fewer parameters. For strain values less than that critical strain, Eq. (3) is valid.

$\sigma_{S}=S \sigma\left(\varepsilon_{c r}, \dot{\varepsilon}, T\right): \quad S<1$

$\sigma_{\text {soft }}(\varepsilon, \dot{\varepsilon}, T)=\sigma-\left(\sigma-\sigma_{s}\right)\left(\tan h\left(k \varepsilon^{*}\right)^{r}\right)$

$\sigma_{\text {soft }}=\sigma(\varepsilon, \dot{\varepsilon}, T)$ for $\varepsilon>\varepsilon_{\text {cr }}$ when $S=1$

$\varepsilon^{*}=\frac{\varepsilon-\varepsilon_{\mathrm{cr}}}{\varepsilon_{\mathrm{cr}}} u(\varepsilon)$ where $u(\varepsilon)=\left\{\begin{array}{l}u(\varepsilon)=0 \text { if } \varepsilon<\varepsilon_{\mathrm{cr}} \\ u(\varepsilon)=1 \text { if } \varepsilon \geq \varepsilon_{\mathrm{cr}}\end{array}\right\}$

The value of $\sigma_{\mathrm{s}}$ (steady state flow stress at high strains) is calculated at the critical strain value for a given temperature and strain rate through Eq. (3) and multiplied with the softening parameter $S$ at the critical strain value as shown in Eq(4). In Eq. (5), $\sigma=\sigma(\varepsilon, \dot{\varepsilon}, T)$ is the proposed material model given in Eq. (3). The critical strain $\left(\varepsilon_{\mathrm{cr}}\right)$ value, after which the softening initiates, has to be defined in order to control the flow softening. The influence of critical strain is controlled by the expression in Eq. (6) through the term $u(\varepsilon)$. For strains higher than the critical strain, flow stress is calculated using Eq. (5).

\section{Methodology}

Design of computer experiments approach is adopted to study the influence of flow softening parameters on the simulation outputs. The influence of temperature based flow stress curves is investigated on the experimental data provided by Cotterell and Byrne (2008a,b). Each material model is tested at two different cutting speeds, and the material model parameters yielding the best match between the simulation and experiments are selected. In the flow softening model, there are four different parameters $\left(k, r, \varepsilon_{\mathrm{cr}}\right.$, and $\left.S\right)$. It is first decided to investigate the temperature dependent influence of the parameter $S$ which defines the level of softening, if softening exists. The parameters $k$ and $r$ are set as 2 . The
Table 3

Material model parameters at different temperature levels.

\begin{tabular}{lllll}
\hline Experiment \# & $T=25^{\circ} \mathrm{C}$ & $T=350{ }^{\circ} \mathrm{C}$ & $T=500{ }^{\circ} \mathrm{C}$ & $T=700{ }^{\circ} \mathrm{C}$ \\
\hline 1 & $S_{1}=0.8$ & $S_{2}=0.8$ & $S_{3}=0.8$ & $S_{4}=0.8$ \\
2 & $S_{1}=0.6$ & $S_{2}=0.6$ & $S_{3}=0.6$ & $S_{4}=0.6$ \\
3 & $S_{1}=1$ & $S_{2}=0.6$ & $S_{3}=0.6$ & $S_{4}=0.6$ \\
4 & Strain hardening & $S_{2}=0.6$ & $S_{3}=0.6$ & $S_{4}=0.6$ \\
5 & Strain hardening & $S_{2}=1$ & $S_{3}=0.6$ & $S_{4}=0.6$ \\
6 & Strain hardening & Strain hardening & $S_{3}=0.6$ & $S_{4}=0.6$ \\
\hline
\end{tabular}

Table 4

Material model parameters with different $k$ and $r$ values.

\begin{tabular}{clc}
\hline Experiment \# & $S($ at all temperature levels) & $k=r$ \\
\hline 7 & 0.6 & 1.1 \\
8 & 0.8 & 1.1 \\
9 & 0.6 & 2.5 \\
10 & 0.8 & 2.5 \\
\hline
\end{tabular}

critical strain values are selected as 0.35 independent from temperature. Table 3 lists the six different experimental cases which will be investigated.

The first and second experimental cases assume that flow softening exists at all temperature levels as assumed in previous studies (i.e. Calamaz et al., 2008) but with different values of the softening parameter $S$. The third experimental case assumes dynamic recovery at room temperature $(S=1)$ but flow softening at all other temperatures. The fourth experimental case assumes strain hardening at room temperature and flow softening at other temperatures. The fifth experimental case assumes strain hardening at room temperature, dynamic recovery at $350^{\circ} \mathrm{C}$, and flow softening at higher temperatures; finally, the sixth experimental case assumes strain hardening at $25^{\circ}$ and $350^{\circ} \mathrm{C}$ and flow softening at other higher temperatures.

As a second group of test, the influence of softening $(S)$ and rate of softening parameters $k$ and $r$ on the finite element simulation outputs are investigated. In order to decrease the number of simulations $k$ and $r$ are taken as equal. Increasing $k$ corresponds to a faster transition from strain hardening to softening. The experimental conditions are listed in Table 4.

\section{Experimental data}

The orthogonal cutting data are selected from the study of Cotterell and Byrne (2008a,b). The titanium alloy Ti6Al4V used in experiments was an extra low interstitial (ELI) grade with an equiaxed $\alpha-\beta$ microstructure and a $10 \mu \mathrm{m}$ grain size. The

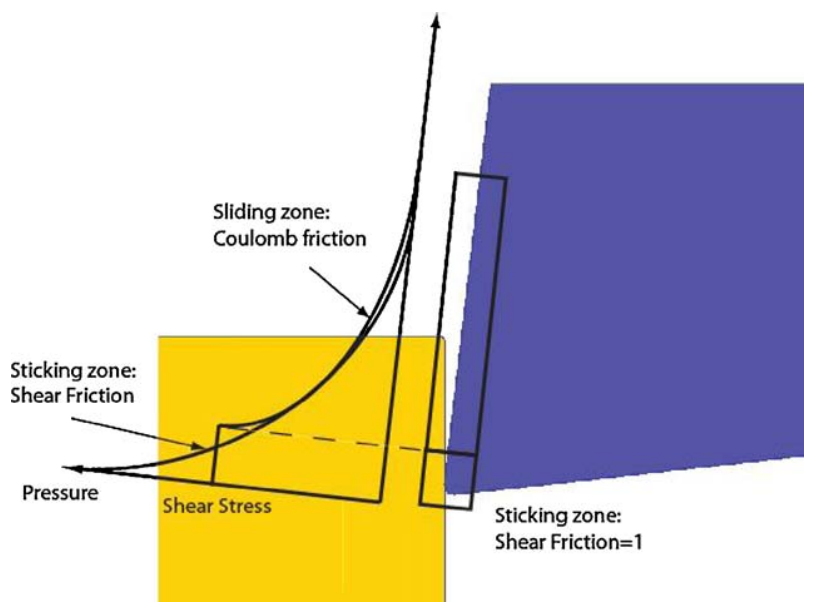

Fig. 3. Friction definition used in the finite element model. 
Table 5

The range of experimental conditions and experimentally measured and calculated process outputs (Cotterell and Byrne, 2008a,b).

\begin{tabular}{|c|c|c|c|c|c|}
\hline \multirow[t]{2}{*}{ Experimental conditions } & & \multicolumn{4}{|c|}{ Experimentally measured/calculated process outputs (for uncut chip thickness of $0.1 \mathrm{~mm}$ ) } \\
\hline & & & $V=120 \mathrm{~m} / \mathrm{min}$ & $V=60 \mathrm{~m} / \mathrm{min}$ & $V=30 \mathrm{~m} / \mathrm{min}$ \\
\hline Uncut chip thickness range (mm) & $0.05,0.075,0.1$ & Shear angle $\left({ }^{\circ}\right)$ (measured) & 40 & 39 & 36 \\
\hline Width of cut (mm) & 2 & Shear stress (MPa) (calculated) & 480 & 510 & 540 \\
\hline Tool edge radius ( $\mu \mathrm{m})$ & $\sim 8$ & Coeff. of friction $(\mu)$ (calculated) & 0.52 & 0.52 & 0.52 \\
\hline Rake angle (deg) & +6.5 & Aver. shear zone temperatures ${ }^{\circ} \mathrm{C}$ (calculated) & 300 & 290 & 280 \\
\hline Cutting speed range (m/min) & $4-140$ & Shear strain (calculated) & 1.6 & 1.65 & 1.8 \\
\hline Tool material & Uncoated carbide & Chip contact length (mm) (measured) & 0.133 & 0.135 & 0.138 \\
\hline
\end{tabular}

material was annealed with a hardness of $340 \mathrm{HV}$ (Cotterell and Byrne, 2008a,b). The experimental conditions and some experimentally measured and calculated process outputs are summarized in Table 5 .
From Table 5, it can be seen that average coefficient of friction is calculated as 0.52 based on experimentally measured thrust and cutting force data, and it seems to be independent of cutting speed from $30 \mathrm{~m} / \mathrm{min}$ to $120 \mathrm{~m} / \mathrm{min}$ at $0.1 \mathrm{~mm}$ uncut chip thick-
Exp. \#

$$
\mathrm{V}=30 \mathrm{~m} / \mathrm{min}
$$

(a)

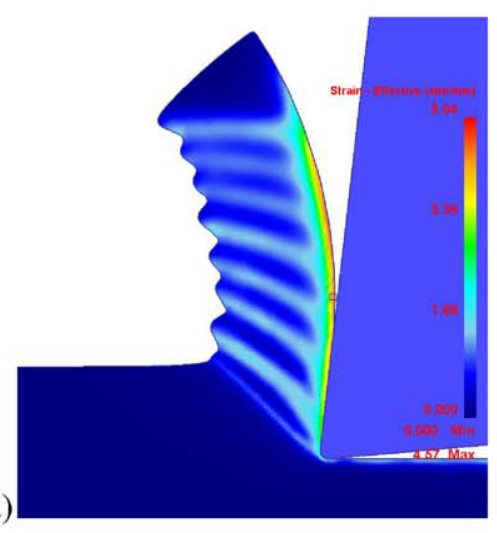

(a)

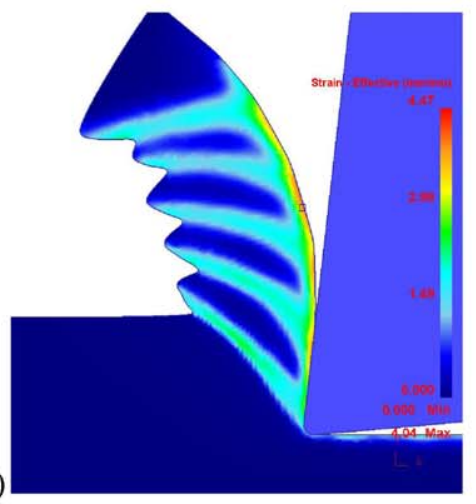

(b)

(b)
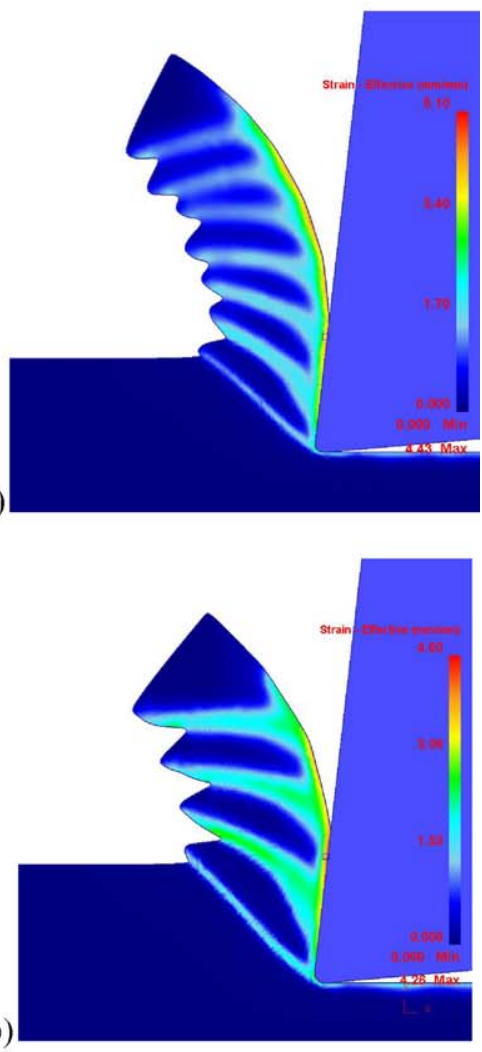

(b)

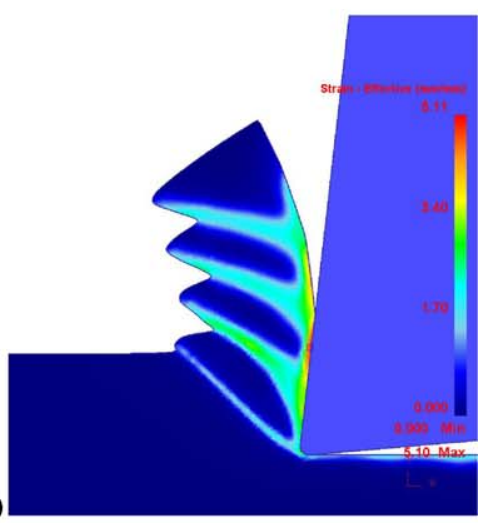

Fig. 4. Effective strain distributions at the cutting zone corresponding to Experiments \#1-\#10. 
4

(a)

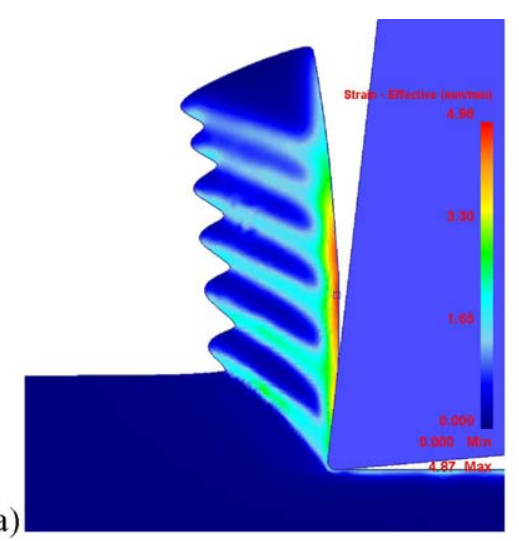

5

(a)

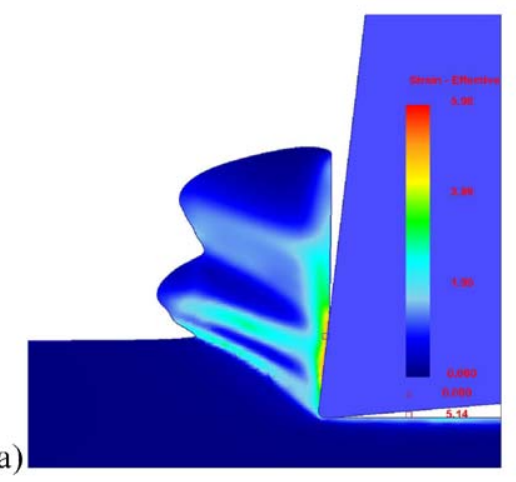

6

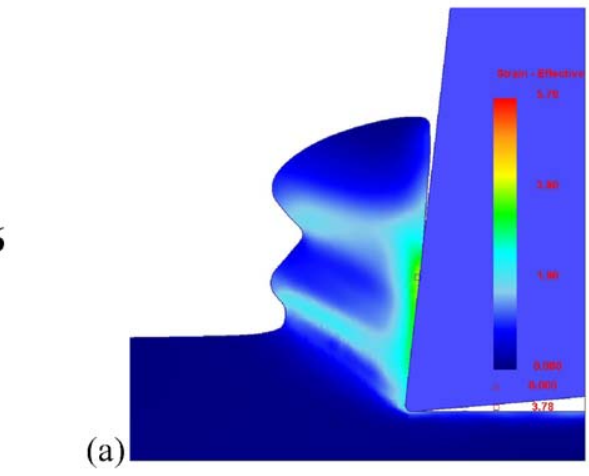

(b)

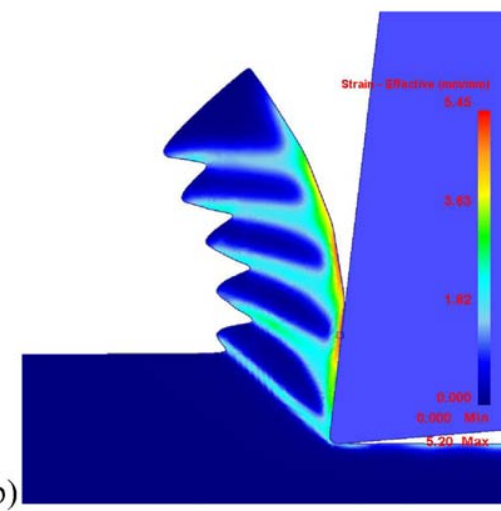

(b)

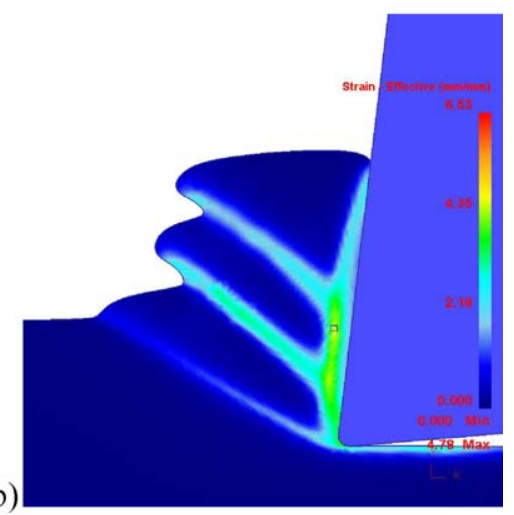

(b)

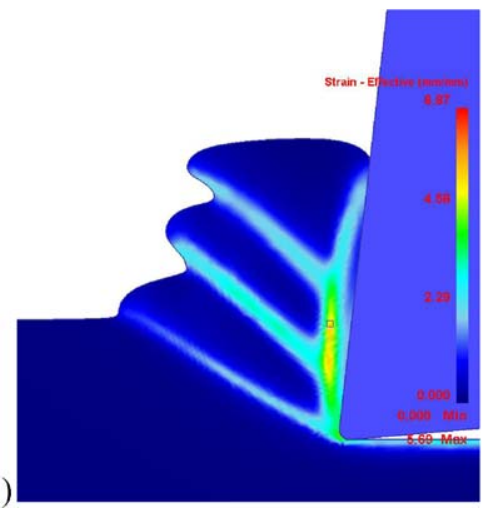

Fig. 4. (Continued)

ness. The average friction coefficient is calculated to be 0.64 when uncut chip thickness is decreased to $0.05 \mathrm{~mm}$ (Cotterell and Byrne, 2008 b). They also analytically calculated average temperature at the primary shear zone as $280-300^{\circ} \mathrm{C}$. The shear stress decreases with increasing cutting speed even though the strain rate nearly triples between $30 \mathrm{~m} / \mathrm{min}$ and $120 \mathrm{~m} / \mathrm{min}$, a change that signifies the importance of thermal softening on the flow stress. The shear angle increases with increasing cutting speed, and shear strain decreases as a result.

\section{Finite element simulation model}

Frictional conditions at the tool-chip and the tool-workpiece interfaces are also important simulation inputs, and a proper definition of friction in finite element models is crucial since it affects the heat generation at the tool-chip and tool-workpiece interfaces. Ozel (2006) demonstrated the importance of various friction definitions on the simulation outputs. In this study, friction is modeled by using the friction window technique as shown in Fig. 3. The length of the sticking zone is selected to be one third of the uncut chip thickness and the Coulomb friction parameter on the sliding zone is selected to be $20 \%$ higher than the calculated average coefficient of friction from machining tests as suggested by Ozlu et al. (2009). In order to have the same average coefficient of friction on the rake face of the tool, a higher coefficient of friction than the calculated average coefficient of friction is defined at the rake face while the friction factor is defined as 1 at the sticking region.

In addition to material constitutive model and friction definition, mechanical and thermo-physical properties of titanium alloy Ti6Al4V are also required in the simulation model, and they are defined as a function of temperature $(T)$ : The Young's modulus $E_{\mathrm{Y}}(T)=-57.7 T+111,672(\mathrm{MPa})$, thermal expansion $\alpha_{T}(T)=3.10^{-9} T+7.10^{-6}\left(1 /{ }^{\circ} \mathrm{C}\right)$, thermal conductivity $\lambda(T)=0.015 T+7.7(\mathrm{~W} / \mathrm{mK})$, heat capacity $C_{p}(T)=2.7 \mathrm{e}^{0.0002 T}$ $\left(\mathrm{N} / \mathrm{mm}^{2} /{ }^{\circ} \mathrm{C}\right)$ (Karpat, 2009). The heat transfer coefficient at the tool-chip interface is taken as a constant $10,000 \mathrm{~W} / \mathrm{m}^{2}{ }^{\circ} \mathrm{C}$. This coefficient is important in terms of calculating temperature distributions in the cutting tool. The workpiece is represented with 
7

(a)

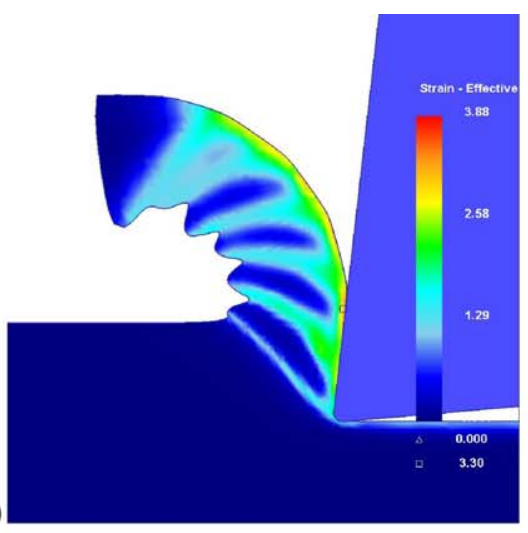

8

(a)

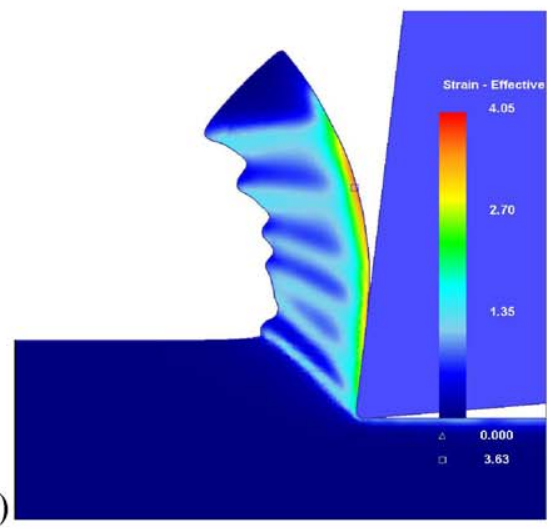

9

(a)

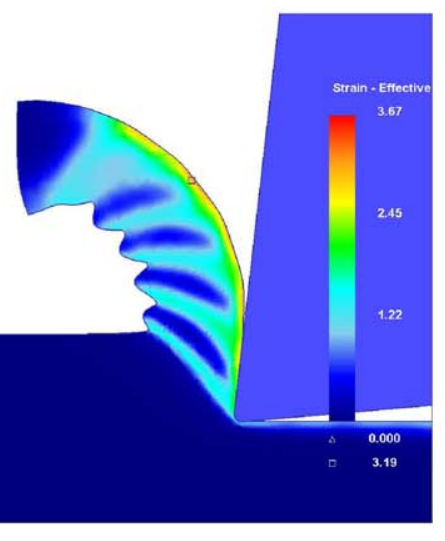

10

(a)

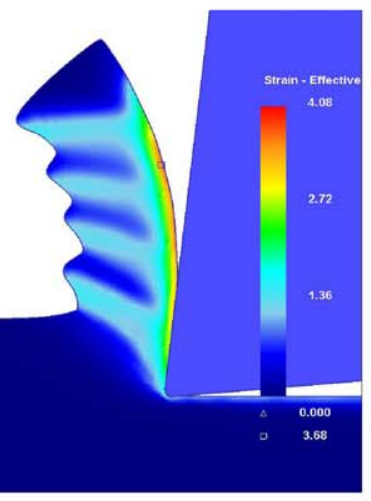

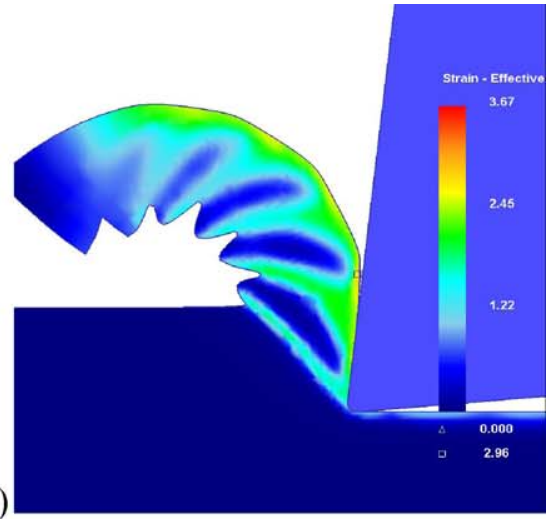

(b)

(b)

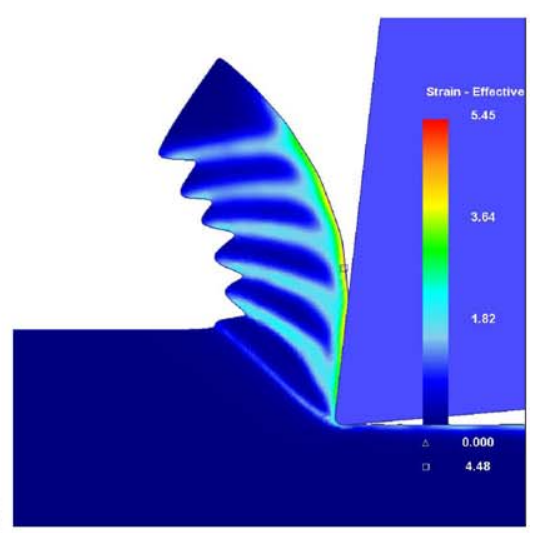

(b)

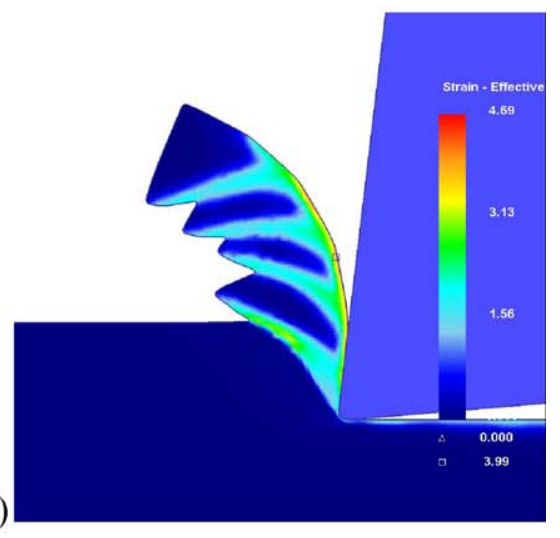

(b)

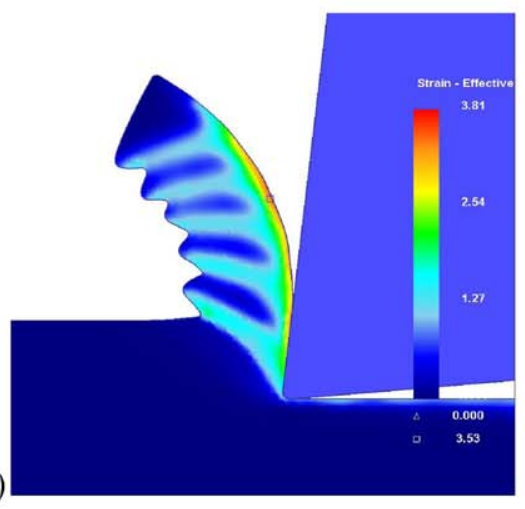

Fig. 4. (Continued). 

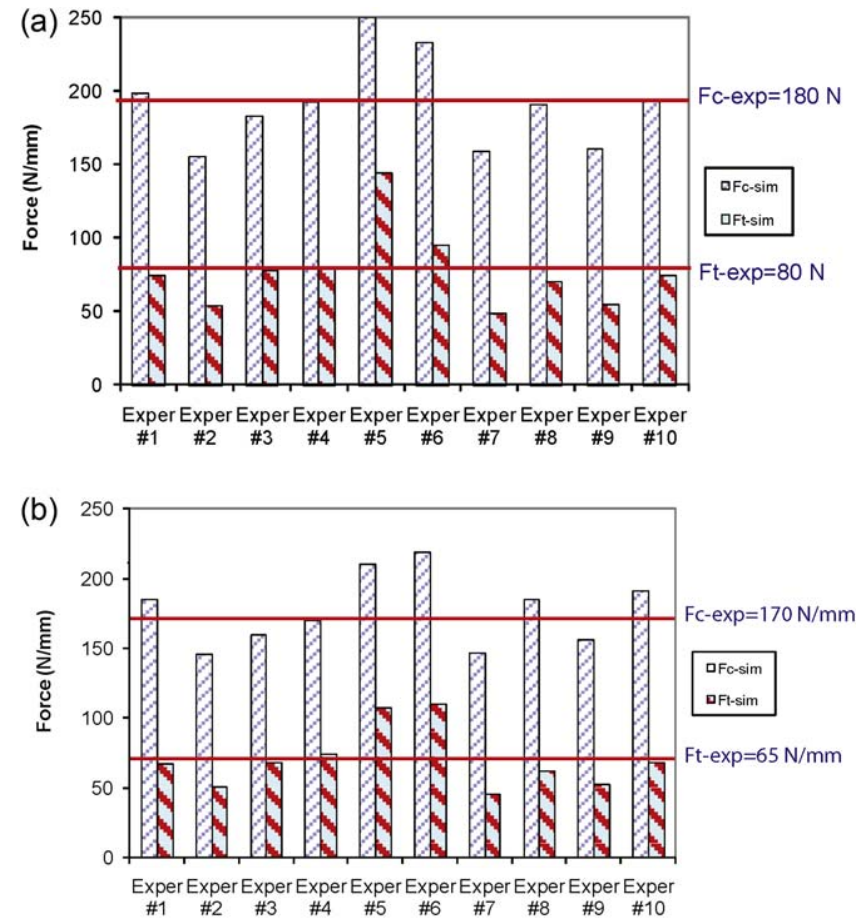

Fig. 5. Simulated cutting $\left(F_{c} / w\right)$ and thrust force $\left(F_{t} / w\right)$ predictions at; (a) $V=30 \mathrm{~m} / \mathrm{min}$ and (b) $V=120 \mathrm{~m} / \mathrm{min}$.

10,000 quadrilateral elements whereas 3500 quadrilateral elements are used to represent the cutting tool. A mesh window is used around the edge radius of the cutting tool for better representation of the tool tip region. The workpiece is modeled as plastic whereas the cutting tool is modeled as rigid. The cutting tool material is uncoated tungsten carbide. Simulations were run on commercial software Deform 2D v9.1. The separation criterion is taken as 0.1 , which is the default value in the Deform software.

\section{Simulation results}

The simulation outputs are compared with the experimental results obtained from the literature at two different cutting speeds. Same friction definition was used in all simulations. According to simulation results given in Fig. 4, it can be seen that temperaturebased softening parameters significantly affect the simulation outputs. Decreasing the softening parameter from 0.8 to 0.6 at all

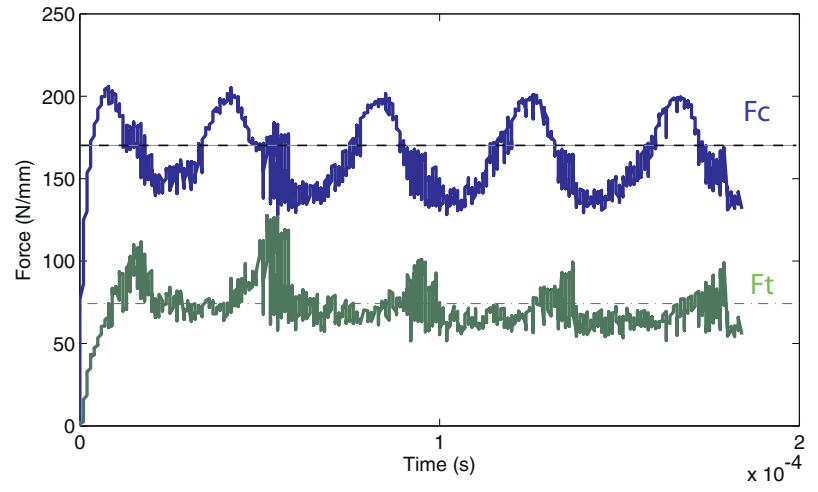

Fig. 6. Variation of cutting forces $\left(F_{c} / w\right)$ with simulation time for Experiment \#4 $\left(V=120 \mathrm{~m} / \mathrm{min}, t_{\mathrm{u}}=0.1 \mathrm{~mm}\right)$.
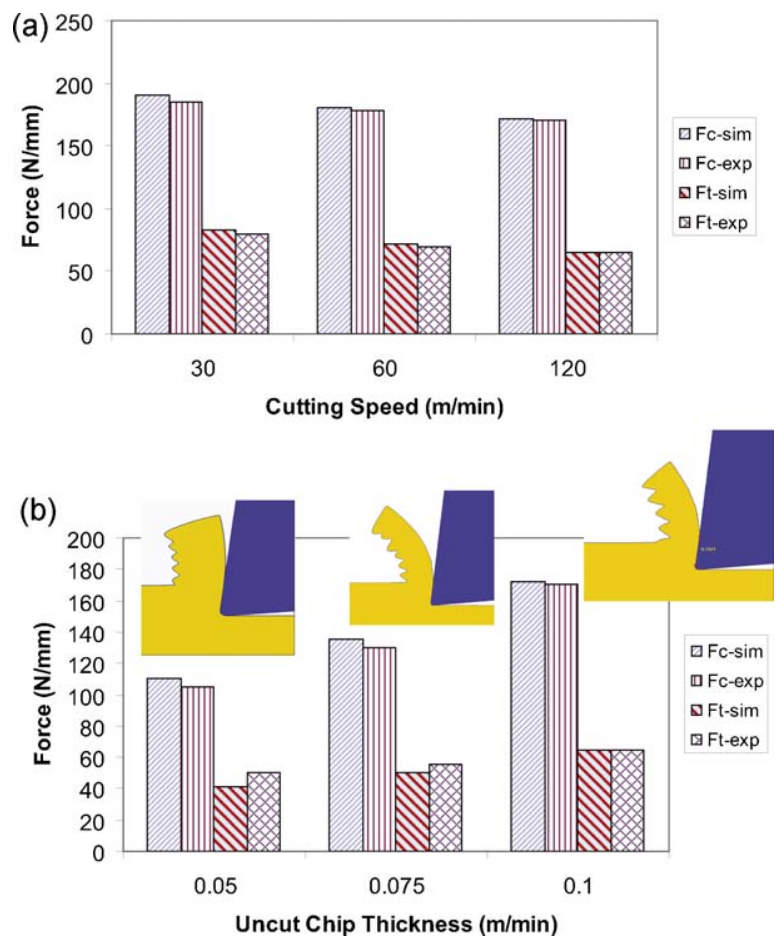

Fig. 7. Comparison of simulated and experimental cutting forces (a) with respect to cutting speed at $t_{\mathrm{u}}=0.1 \mathrm{~mm}$ and (b) with respect to uncut chip thickness at $V=120 \mathrm{~m} / \mathrm{min}$ with simulated chips (Cotterell and Byrne, 2008a,b).

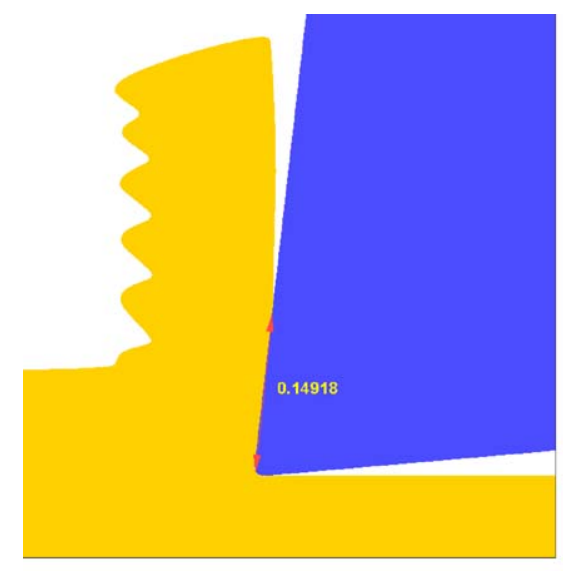

(a)

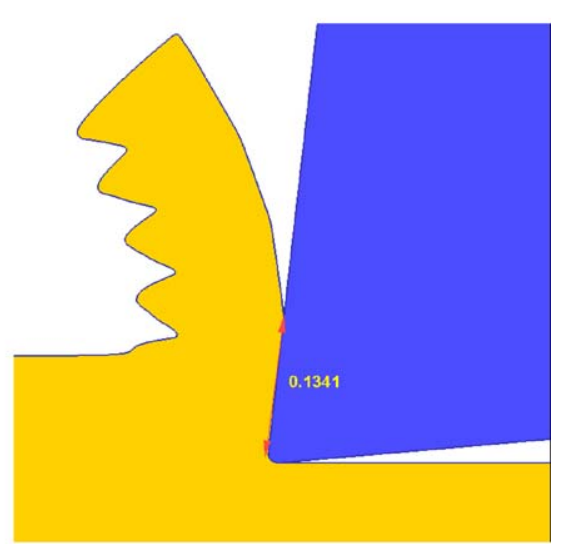

(b)

Fig. 8. Comparison of tool-chip contact length at two different cutting speeds when uncut chip thickness is $0.1 \mathrm{~mm}$; (a) $V=30 \mathrm{~m} / \mathrm{min}$ and (b) $V=120 \mathrm{~m} / \mathrm{min}$. 
temperature levels produces more serrated chips at $30 \mathrm{~m} / \mathrm{min}$ and $120 \mathrm{~m} / \mathrm{min}$, and chips tend to be more curved with higher softening (Experiments \#1 and \#2). Introducing no strain hardening at room temperature and strain hardening at room temperature yielded similar results in terms of chip morphology (Experiments $\# 2$ and \#4). The chips simulated in Experiment \#4 are straighter than those obtained in Experiments \#1 and \#2 and there is still significant serration at $30 \mathrm{~m} / \mathrm{min}$ cutting speed. With no strain hardening or when strain hardening is introduced at $350^{\circ} \mathrm{C}$ (Experiments \#5 and \#6), the chips become thicker and less serrated, especially at $30 \mathrm{~m} / \mathrm{min}$. This phenomenon is related to the decreasing temperatures at the primary deformation zone at lower cutting speeds.

The finite element simulation results for the second group of experiments (Experiments \#7-\#10), where the effect of rate of softening parameters are investigated, are shown in Fig. 4. For example, Experiments \#2, \#7, and \#9 have the same $S$ value but different $k$ (and $r$ ) values. It is observed that the softening parameters ( $k$ and $r$ ) influence the serrated chip formation and in some cases are responsible for forming irregular serrations. Their effect is less significant at $120 \mathrm{~m} / \mathrm{min}$ cutting speed. It is obvious that softening parameter $S$ has a more dominant effect on the serrated chip formation than the softening parameters $k$ and $r$.

Fig. 5 compares of simulated cutting forces in each tested case for two different cutting speed levels. By considering the cutting forces and chip shape, temperature dependent softening parameters given in Experiment \#4 are selected as material model parameters. It can be noted that introducing strain hardening at room temperature improved thrust force predictions compared to Experiments \#2 and \#3. The same friction definition was used in the simulations as per the results given in Table 5. The simulation results of Experiments \#2 and \#3 can be increased by increasing the coefficient of friction on the sliding region. However, by doing so, the friction definition becomes different from the experimental average friction value.

From these findings, it can be concluded that the degree of flow softening initiating from $350^{\circ} \mathrm{C}$ significantly affects the simulation force outputs. When flow softening is initiated from $500^{\circ} \mathrm{C}$, even though serrated chips are simulated, the cutting force calculations do not agree well with the experimental force measurements. Strain hardening at room temperature does not affect the cutting force $\left(F_{c}\right)$ but slightly increases the thrust force $\left(F_{t}\right)$ predictions.

Fig. 6 shows the fluctuation of cutting forces with respect to time. Serrated chip formation affects the cutting forces. An increase in cutting and thrust forces corresponds to the initiation phase of serrated chip formation. According to simulation results, the chip formation frequency (number of serrated chips per unit time) are calculated as $7751 \mathrm{~Hz}$ at $30 \mathrm{~m} / \mathrm{min}$ cutting speed and $28,571 \mathrm{~Hz}$ at the $120 \mathrm{~m} / \mathrm{min}$ cutting speed, which agrees well with the experimental data given in Cotterell and Byrne (2008a). It is observed that there is an almost linear relationship between cutting speed and chip formation frequency.

Fig. 7 shows the comparison of simulated and experimental cutting forces at all cutting conditions. It can be seen that finite element simulation yields results that are in good agreement with the experimental results. The maximum error is about $20 \%$ when uncut chip thickness is decreased to $0.05 \mathrm{~mm}$. In that case, the length of sticking zone may need to be changed to match the simulation results with the experimental ones. The amount of chip serration decreases with decreasing uncut chip thickness and decreasing cutting speed as shown in Fig. 7(b).

Fig. 8 reveals the tool-chip contact length at two different cutting conditions. Tool-chip contact length slightly decreases with increasing cutting speed. When compared with the measurements given in Table 5, the finite element simulation predicts tool-chip contact length reasonably well. (a)

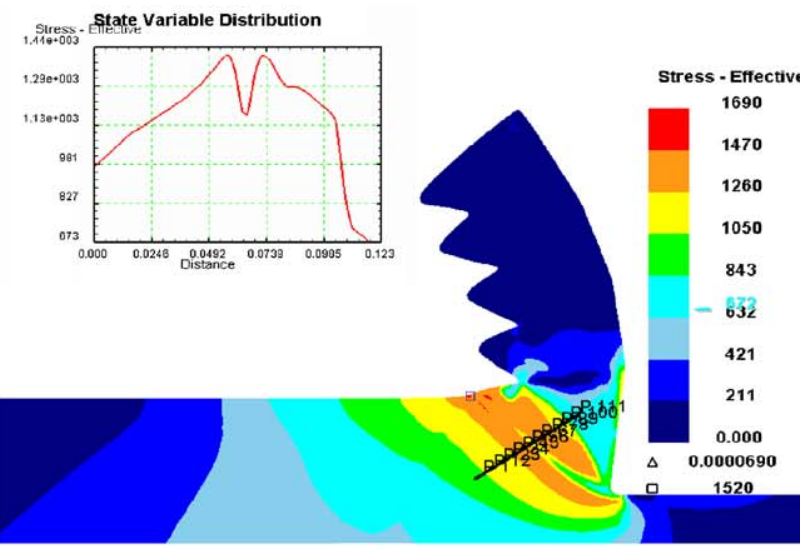

(b)

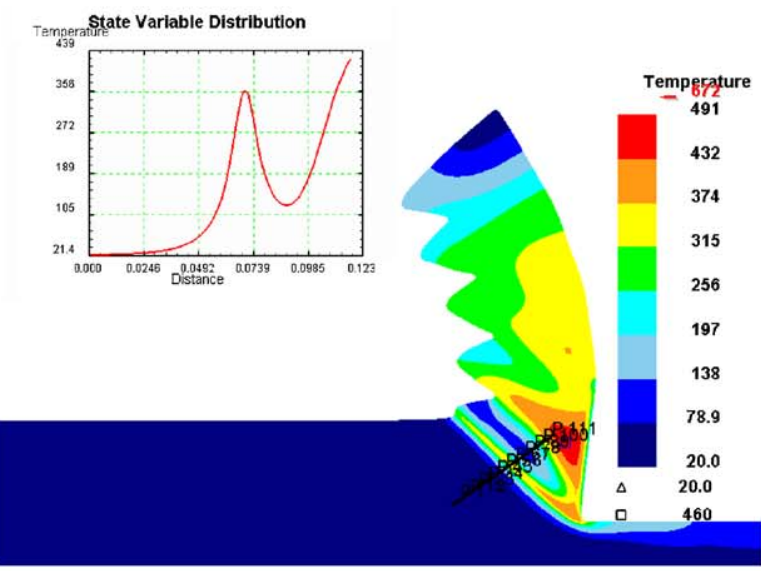

(c)

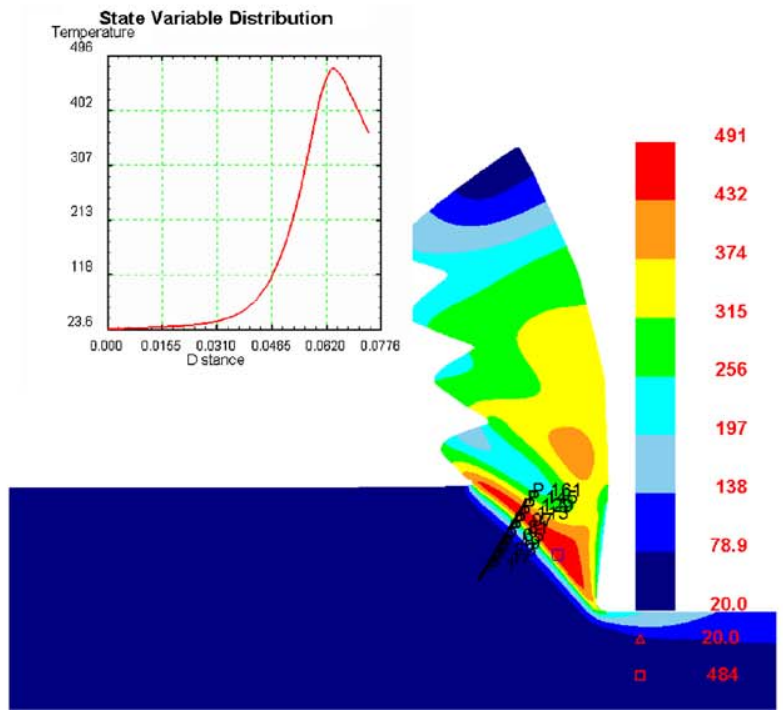

Fig. 9. (a) Stress distribution, (b) temperature distribution at the beginning of shear band formation, and (c) temperature distribution at the end of shear band formation for the condition of $V=120 \mathrm{~m} / \mathrm{min}$ and $t_{\mathrm{u}}=0.1 \mathrm{~mm}$ (Stress in MPa, tempeature in ${ }^{\circ} \mathrm{C}$ ).

Fig. 9(a-c) shows the effective stress and temperature distributions across the adiabatic shear band at the cutting speed of $120 \mathrm{~m} / \mathrm{min}$. The flow stress drop due to softening can be seen in Fig. 9(a). Fig. 9(b) shows the corresponding temperature rise which causes that effective stress drop at the initiation of the shear band. Fig. 9(c) shows the end of the shear band formation where the temperature increase reaches $490^{\circ} \mathrm{C}$ which is in the range of critical temperature for dynamic recrystallization (Liao and Duffy, 1998). The temperature and effective stress calculations are in accordance with the material properties used in finite element models. The 
(a)

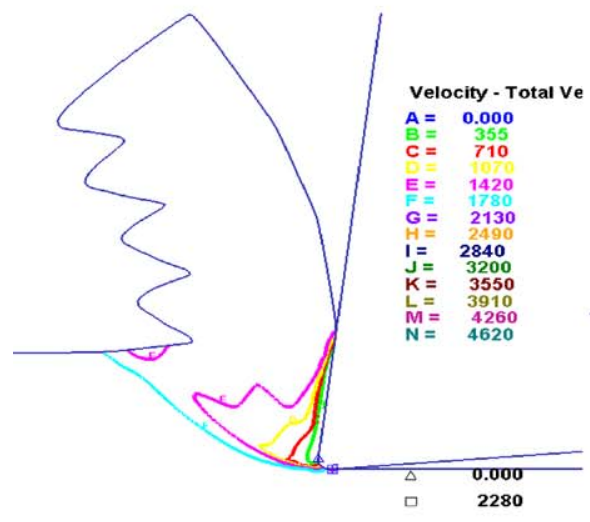

(b)

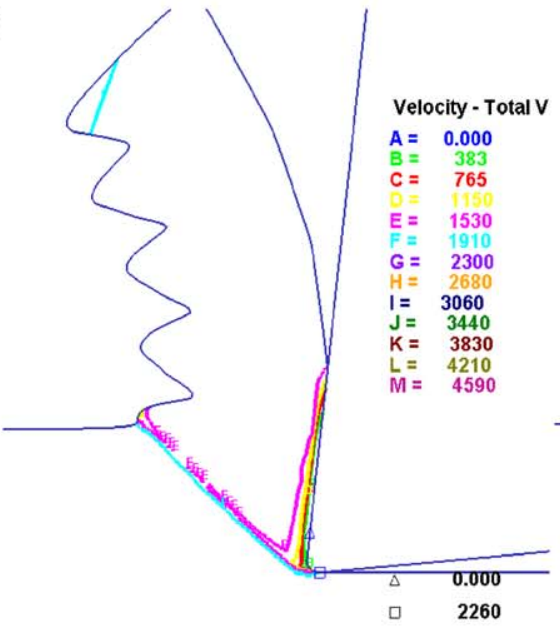

(c)

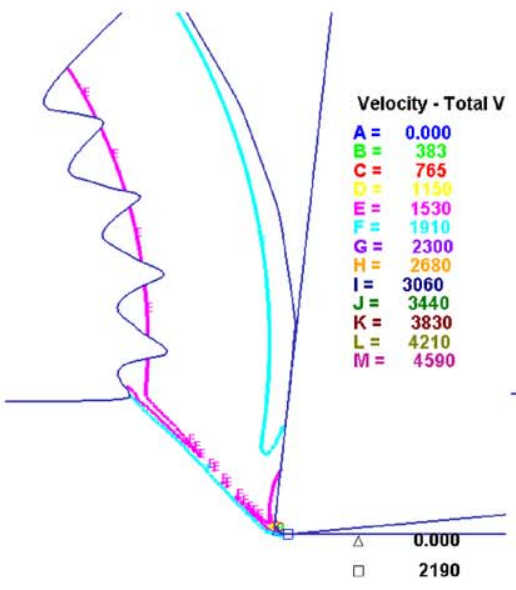

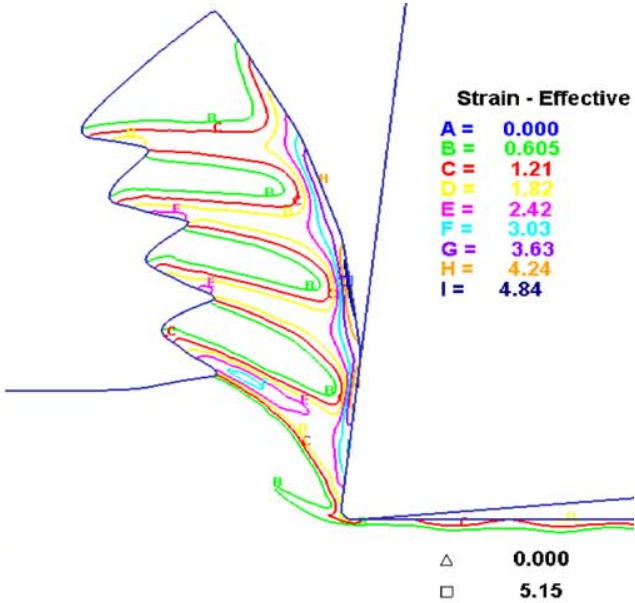
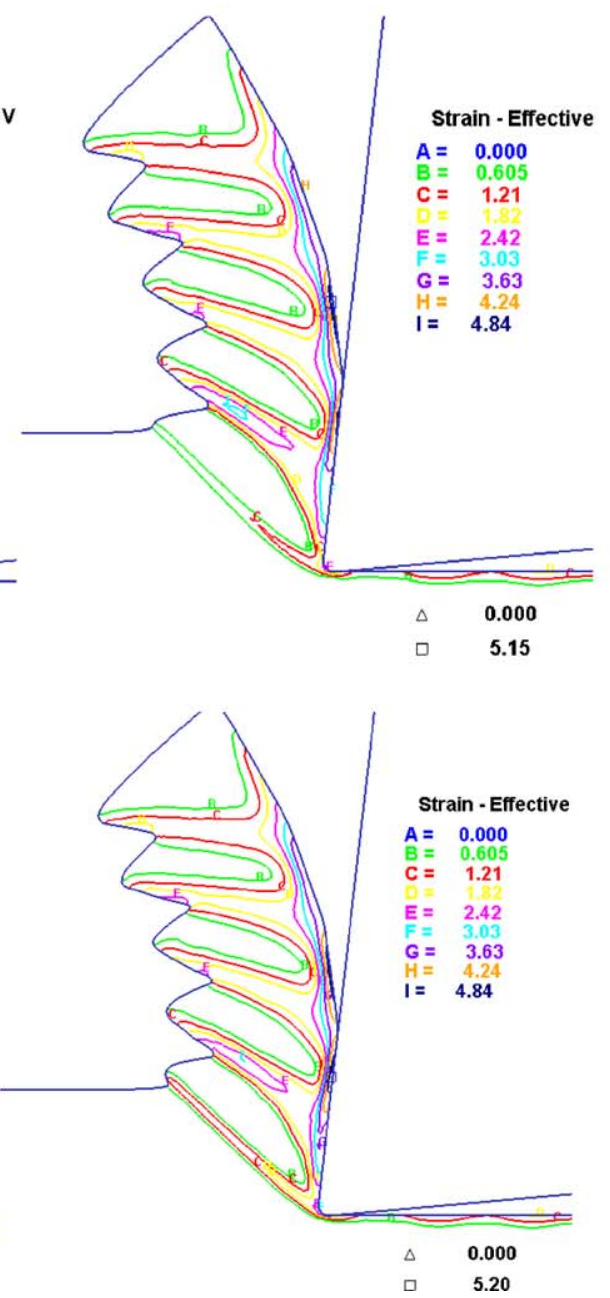

Fig. 10. Velocity and strain distributions during serrated chip formation process $\left(V=120 \mathrm{~m} / \mathrm{min}, t_{\mathrm{u}}=0.1 \mathrm{~mm}\right)$.

thickness of the adiabatic shear band can be measured as $20 \mu \mathrm{m}$ from Fig. 8(a).

Fig. 10 shows the strain distributions at the cutting zone during the different phases of the serrated chip formation process. The serrated chip formation process starts when the material starts to rise in front of the cutting tool as shown in Fig. 10(a). Fig. 10(b) shows initiation of the serrated chip formation, which starts from the outer surface of the chip when the shear band reaches that point. The temperature at the outer surface of the chip at this instant is obtained from the finite element simulation to be around $150-160^{\circ} \mathrm{C}$. The strain value at the lower shear band boundary is calculated in the simulation to be around 0.6 . This corresponds to the strain value where the flow stress reaches a steady state after a steep drop from the peak stress in the strain-stress diagram which is controlled by $k$ and $r$ in the material model. The strain inside the shear band rapidly increases to 1.5-1.7 (Fig. 10(c)) and the temperature inside the shear band varies between 350 and $500^{\circ} \mathrm{C}$. The serrated chip formation process continues in a cyclical manner. 


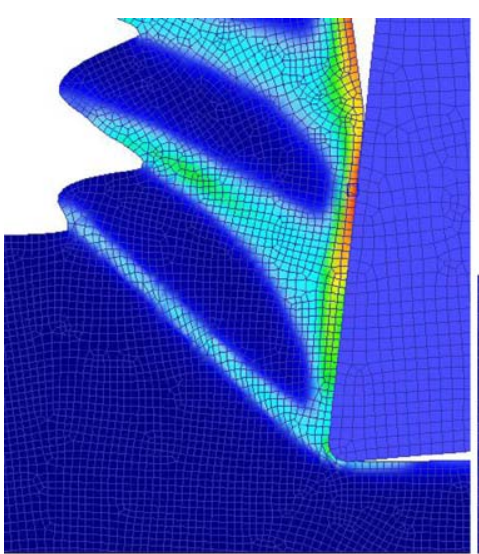

(a)

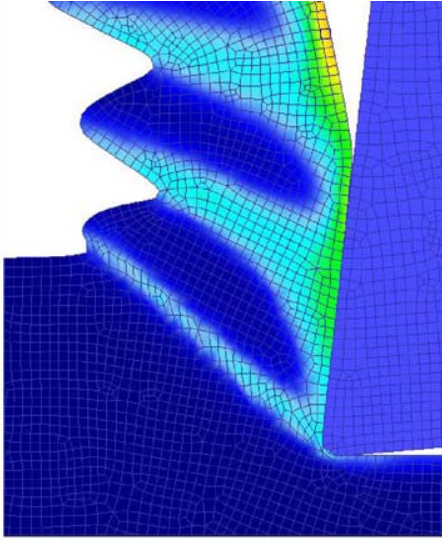

(b)

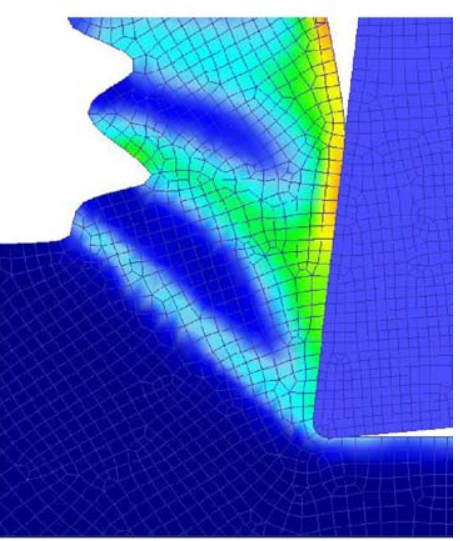

(c)

Fig. 11. Influence of number of elements on the shear band formation: (a) 10,000 elements, (b) 5000 elements and (c) 2500 elements $\left(V=120 \mathrm{~m} / \mathrm{min}, t_{\mathrm{u}}=0.1 \mathrm{~mm}\right)$.

(a)

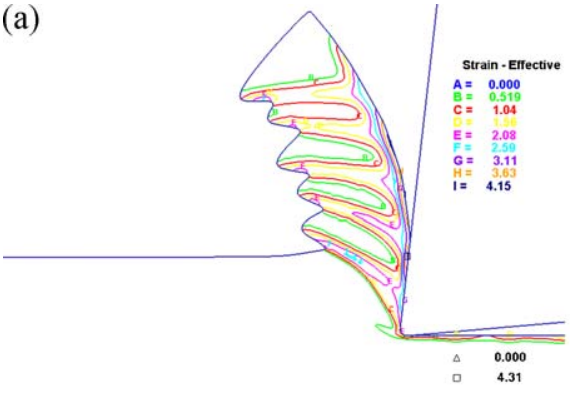

(b)

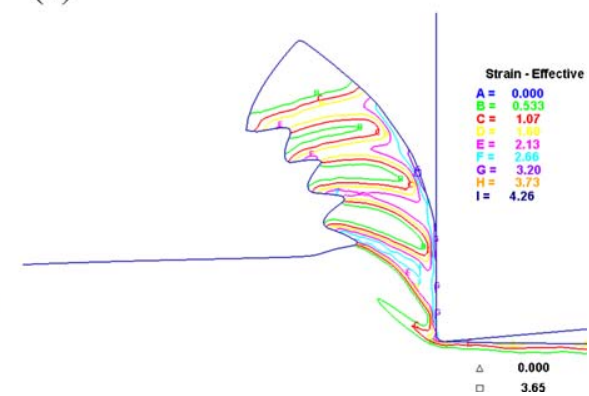

Fig. 12. Effective strain distributions at $V=60 \mathrm{~m} / \mathrm{min}$, (a) Cotterell and Byrne (2008b) and (b) Nouari et al. (2008).

The frictional conditions at the tool-chip interface also affect the chip formation process. During the first stage, the material temporarily sticks to the rake face of the tool because of the sticking friction region defined in the model (Fig. 10(a)). A different friction definition changes the chip morphology.

In all of the simulations mentioned above the maximum number of elements $(10,000)$ allowed in finite element simulation software was used. It is known that the shear band formation is closely related to the mesh density used in the simulation. The number of elements in the finite element model decreased from 10,000 to 5000 and 2500, and the resulting shear band and chip formation are shown in Fig. 11. As the number of elements used in the simulations decreases, shear bands are still formed, but the degree of serration is decreased and the thickness of the shear band is increased.

\subsection{Further validation of the material model parameters}

The material model parameters are further tested on other experimental data from the literature where a zero rake angle cutting tool was used as in Nouari et al. (2008). Table 5 shows the experimental cutting conditions used in this study. Table 6 summarizes the measured cutting and thrust forces at uncut chip thickness of $0.1 \mathrm{~mm}$.

The results obtained from finite element simulation are shown in Fig. 12. A cutting speed that was not used in testing material model parameters ( $60 \mathrm{~m} / \mathrm{min}$ ) was used for comparison purposes. Due to employing a zero rake angle cutting tool, a slightly higher level of chip serration was observed. In these simulations, frictional conditions were also defined as sticking zone, $30 \%$ of uncut chip thickness, and coefficient of friction $20 \%$ more than the experimental average coefficient of friction.
Table 6

Experimental cutting conditions.

\begin{tabular}{ll}
\hline & Nouari et al. (2008) \\
\hline Uncut chip thickness $(\mathrm{mm})$ & 0.1 \\
Width of cut $(\mathrm{mm})$ & 4 \\
Tool edge radius $(\mu \mathrm{m})$ & $5-10$ \\
Rake angle $\left({ }^{\circ}\right)$ & 0 \\
Cutting speed $(\mathrm{m} / \mathrm{min})$ & 30,60 \\
Tool material & Uncoated carbide \\
\hline
\end{tabular}

Fig. 13 shows the comparison of the measured and simulated cutting forces for the dataset of Nouari et al. (2008).

According to force measurements given in Table 7 and predictions obtained from the simulations, there is a disagreement in terms of cutting forces between Cotterell and Byrne and Nouari et al. at $30 \mathrm{~m} / \mathrm{min}$ cutting speed. Measuring higher cutting forces is expected when a zero rake angle cutting tool is used, but the cut-

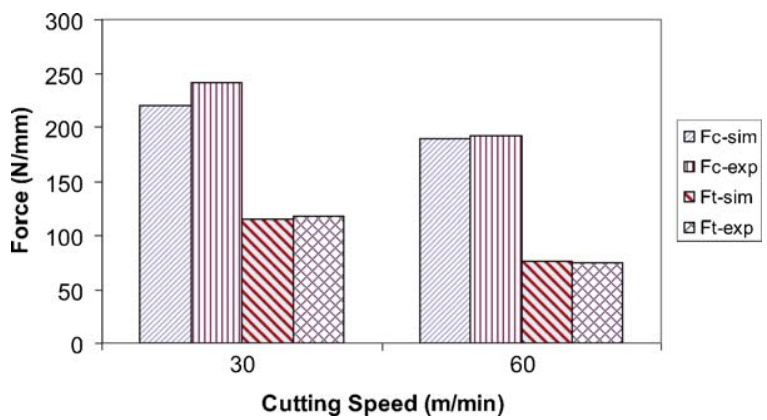

Fig. 13. Comparison of experimental and simulated cutting forces (Nouari et al. (2008)). 
Table 7

Comparison of measured cutting and thrust forces ( $t_{\mathrm{u}}$ is selected as $0.1 \mathrm{~mm}$ at all tests).

\begin{tabular}{|c|c|c|c|c|c|}
\hline & \multicolumn{3}{|c|}{ Cotterell and Byrne (2008a,b) } & \multicolumn{2}{|c|}{ Nouari et al. (2008) } \\
\hline & \multicolumn{5}{|c|}{ Cutting speed (m/min) } \\
\hline & 30 & 60 & 120 & 30 & 60 \\
\hline Cutting force $F_{c}(\mathrm{~N} / \mathrm{mm})$ & 180 & 175 & 170 & 242 & 200 \\
\hline Thrust force $F_{t}(\mathrm{~N} / \mathrm{mm})$ & 75 & 70 & 65 & 117 & 75 \\
\hline
\end{tabular}

ting force measurement is significantly higher in Nouari et al. In this condition, the level of error is about \%15, an acceptable level in machining research. However, the other predictions agree very well with the experimental data. These findings suggest that simulation results are more sensitive to the material model than the friction definition. The friction definition adopted in this study yielded good results with the experimental cutting cases considered.

\section{Conclusions and discussion}

In this study, temperature dependent flow softening behavior of titanium alloy Ti6Al4V is investigated using finite element simulations of machining. The influence of material model parameters is investigated through simulations. Temperature dependent flow softening parameters are validated on an experimental dataset at two different cutting speeds and three different uncut chip thickness values. The material model parameters are further tested on another experimental dataset obtained with a different rake angle cutting tool. It is shown that finite element models are capable of producing reliable results if material model and friction are defined properly. In addition it is shown that:

- The case where flow softening initiates around $350^{\circ} \mathrm{C}$ yielded the most realistic simulation results. The temperature rise within the shear band reaches to $490^{\circ} \mathrm{C}$ for the cutting speed tested in this study. This agrees well with the findings in the literature. The strain in the shear band is shown to be in the level of 1.5-1.7.

- Flow softening at room temperature does not influence the simulation outputs significantly but is shown to increase chip serration, produce more curved chips, and decrease thrust force predictions.

- Friction definition based on an experimentally calculated average coefficient of friction produced good results for the cases of machining with low rake angle cutting tools with small edge radii.

- It is possible to simulate serrated chips without using a damage model. However, not including damage models in the analysis does not rule out the influence of ductile fracture during adiabatic shear band propagation.

The results obtained in this study suggest that the critical temperature for the initiation of softening and the level of softening both have a strong influence on the finite element simulations when machining titanium alloy Ti6Al4V. In the literature, the flow softening has been attributed to dynamic recrystallization where a critical temperature, strain, and strain rate must be attained to initiate shear band formation. Those critical values may be a function of the initial microstructure of the titanium alloy. It must be noted that the flow softening initiating at $350^{\circ} \mathrm{C}$ is lower than the critical recrystallization temperatures reported in the literature. However, in a recent study, it is shown that increasing strain rate decreases the critical temperature (Medyanik et al., 2007). Similarly, flow softening at room temperature, as adopted by many other studies in the literature, must have an underlying explanation. Therefore, more research is needed in this area to clarify the issues related to flow softening occurring at low temperatures. Titanium alloy Ti6Al4V specimens with different initial microstruc- tures used in the experimental study may help to shed light on this discussion.

\section{Acknowledgements}

The author would like to acknowledge the financial support from The Scientific and Technological Research Council of TurkeyTUBITAK. The author would also like to thank Prof. G. Byrne and Dr. M. Coterell for providing orthogonal cutting test data.

\section{References}

Altintas, Y., Eynian, M., Onozuka, H., 2008. Identification of dynamic cutting force coefficients and chatter stability with process damping. CIRP Annals - Manufacturing Technology 57 (1), 371-374.

Anurag, S., Guo, Y.B., 2007. A modified micromechanical approach to determine flow stress of work materials experiencing complex deformation histories in manufacturing processes. International Journal of Mechanical Sciences 49 (7), 909-918.

Bäker, M., Rösler, J., Siemers, C., 2002. A finite element model of high speed meta cutting with adiabatic shearing. Computers \& Structures 80 (5-6), 495-513.

Calamaz, M., Coupard, D., Girot, F., 2008. A new material model for 2D numerical simulation of serrated chip formation when machining titanium alloy Ti-6Al-4V. International Journal of Machine Tools \& Manufacture 48, 275-288.

Calamaz, M., Coupard, D., Girot, F., 2010. Numerical simulation of titanium alloy dry machining with a strain softening constitutive law. Machining Science and Technology 14 (2), 244-257.

Chen, L., El-Wardany, T.I., Harris, W.C., 2004. Modelling the effects of flank wear land and chip formation on residual stresses. CIRP Annals - Manufacturing Technology 53 (1), 95-98.

Childs, T.H.C., 2009. Modelling orthogonal machining of carbon steels. Part I: strain hardening and yield delay effects. International Journal of Mechanical Sciences 51 (5), 402-411.

Cotterell, M., Byrne, G., 2008a. Dynamics of chip formation during orthogonal cutting of titanium alloy Ti-6Al-4V. CIRP Annals 57 (1), 93-96.

Cotterell, M., Byrne, G., 2008b. Characterisation of chip formation during orthogona cutting of titanium alloy Ti-6Al-4V. In: 3rd CIRP International Conference High Performance Cutting, Dublin, Ireland June 12th-13th.

Deform 2D Version 9.1, 2008. Scientific Forming Technologies Corporation, Columbus, Ohio, USA.

Giovanola, H., 1988. Adiabatic shear banding under pure shear loading, part II: fractographic and metallographic observations. Mechanics of Materials 7, 73-87.

Johnson, G.R., Cook, W.H., 1983. A constitutive model for metals subjected to large strains, high strain rates and high temperatures. In: Proceedings of the Seventh International Symposium, vol. 54, Ballis, Hague, Netherlands, pp. 1-7.

Karpat, Y., 2009. Finite element modeling of machining Ti-6Al-4V alloy using a modified material model. In: 12th CIRP Conference on Modeling of Machining Operations, May 7-8 2009, San Sebastian, Spain.

Komanduri, R., Turkovich, B.F., 1981. New observations on the mechanism of chip formation when machining titanium alloys. Wear 69, 179-188.

Lee, W., Lin, C., 1998. High-temperature deformation behavior of Ti6Al4V alloy evaluated by high strain-rate compression tests. Journal of Materials Processing Technology 75, 127-136.

Li, L., He, N., 2006. A FEA study on mechanisms of saw-tooth chip deformation in high speed cutting of Ti-6-Al-4V alloy. In: Fifth International Conference on High Speed Machining (HSM), Metz, France, 14-16 March 2006, pp. 759-767.

Liao, S.C., Duffy, J., 1998. Adiabatic shear bands in a Ti6Al4V titanium alloy. Journal of the Mechanics and Physics of Solids 35 (11), 2201-2231.

Medyanik, S.N., Liu, W.K., Li, S., 2007. On criteria for dynamic adiabatic shear band propagation. Journal of the Mechanics and Physics of Solids 55, 1439-1461.

Meyer, H.W., Kleponis, D.S., 2001. Modeling the high strain rate behavior of titanium undergoing ballistic impact and penetration. International Journal of Impac Engineering 26, 509-521.

Miller, R.M., Bieler, T.R., Semiatin, S., 1999. Flow softening during hot working of Ti-6Al-4V with a lamellar colony microstructure. Scripta Materiala 40 (12) 1387-1393.

Nouari, M., Calamaz, M., Girot, F., 2008. Wear mechanisms of cutting tools used in the dry machining of the aeronautic titanium alloy, Ti-6Al-4V. Comptes Rendus Mécanique 336 (10), 772-781. 
Ozel, T., Zeren, E., 2004. Determination of work material flow stress and friction properties for FEA of machining using orthogonal cutting tests. Journal of Materials Processing Technology 153, 1019-1025.

Ozel, T., 2006. Influence of friction models on finite element simulations of machining. International Journal of Machine Tools and Manufacture 46 (5), 518-530.

Ozlu, E., Budak, E., Molinari, A., 2009. Analytical and experimental investigation of rake contact and friction behavior in metal cutting. International Journal of Machine Tools and Manufacture 49, 865-875.

Rhim, S.H., Oh, S.I., 2006. Prediction of serrated chip formation in metal cutting process with new flow stress model for AISI 1045 steel. Journal of Materials Processing Technology 171, 417-422.

Rittel, D., Landau, P., Venkert, A., 2008. Dynamic recrystallization as a potential cause for adiabatic shear failure. Physical Review Letters 101, 165501.

Seo, S., Min, O., Yang, H., 2005. Constitutive equation for Ti-6Al-4V at high temperatures measured using the SHPB technique. International Journal of Impact Engineering 31, 735-754.
Shivpuri, R., Hua, J., Mittal, P., Srivastava, A.K., 2001. Microstructure-mechanics interactions in modeling chip segmentation during titanium machining. CIRP Annals 51, 85-89.

Song, H.W., Zhang, S.H., Cheng, M., 2009. Dynamic globularization kinetics during hot working of a two phase titanium alloy with a colony alpha microstructure. Journal of Alloys and Compounds 480, 922-927.

Umbrello, D., 2008. Finite element simulation of conventional and high speed machining of Ti6Al4V alloy. Journal of Materials Processing Technology 196 (1-3), 79-87.

Wang, H., To, S., Chan, C.Y., Cheung, C.F., Lee, W.B., 2010. Elastic strain induced shear bands in the microcutting process. International Journal of Machine Tools and Manufacture 50 (1), 9-18.

Xu, Y., Zhang, J., Bai, Y., Meyers, M.A., 2008. Shear localization in dynamic deformation: microstructural evolution. Metallurgical and Materials Transactions 39A, 811. 